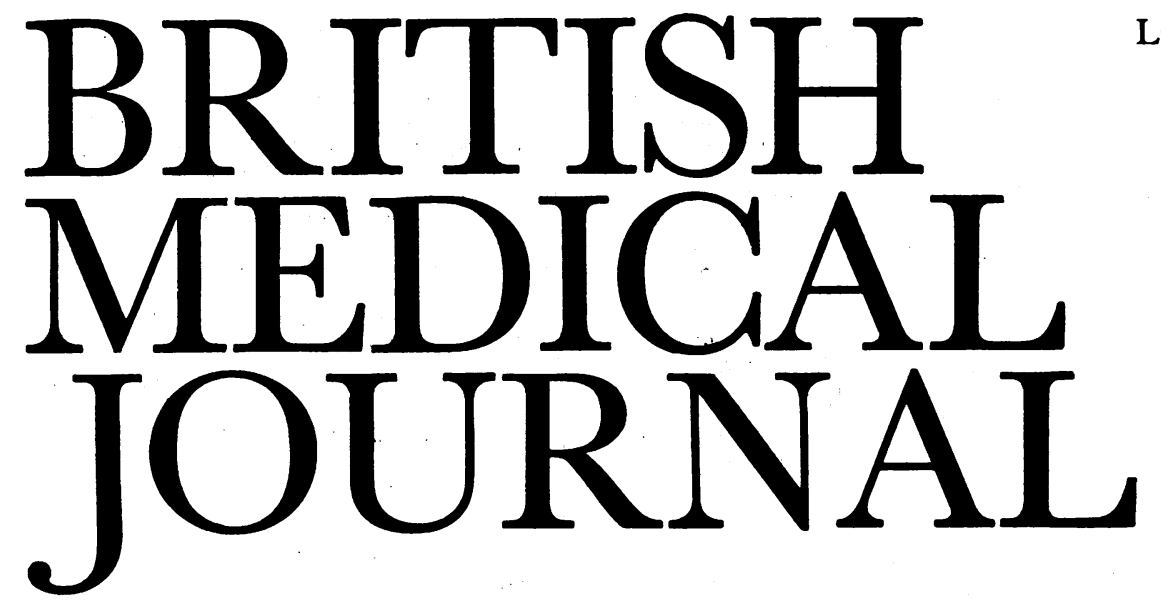

LONDON, SATURDAY 10 OCTOBER 1987

\title{
Treatment in primary biliary cirrhosis
}

In primary biliary cirrhosis the small interlobular bile ducts are destroyed by chronic inflammation. ${ }^{1}$ The disease is characterised by gradually increasing cholestasis with the eventual development of cirrhosis and its complications of liver failure and portal hypertension. Current treatment seeks to relieve symptoms, prevent or relieve the consequences of prolonged cholestasis, treat liver failure and the complications of portal hypertension, and eventually replace the destroyed liver.

Asymptomatic patients need none of this treatment, but thyroid function should be assessed in patients with fatigue, as hypothyroidism is common. ${ }^{2}$ Pruritus is the main symptom requiring treatment, and most patients benefit substantially from cholestyramine. ${ }^{3-5}$ Those patients who do not get adequate relief may benefit from ultraviolet light ${ }^{6}$ or from plasmapheresis. ${ }^{7}$ Antihistamines are usually ineffective, but terfenadine has been reported as beneficial. ${ }^{8}$ Nutritional deficiency may arise from anorexia and malabsorption in patients with more severe cholestasis, especially in those with jaundice. Malabsorption affects particularly fat and fat soluble nutrients, ${ }^{9}$ and patients may require supplements of calcium and vitamin $D,{ }^{10}$ vitamin $K$, and perhaps vitamin $\mathrm{A},{ }^{11}$ and restriction of fat intake to $\mathbf{4 0} \mathrm{g}$ /day usually helps those with steatorrhoea. The rare complications of large xanthomas and xanthomatous neuropathy are relieved by plasmapheresis.?

The consequences of liver failure and portal hypertension are treated as in any other form of cirrhosis, but the prognosis is poor. Given, however, that patients with primary biliary cirrhosis are usually free of disease outside the liver, they are suitable for liver transplantation, which offers about a $60 \%$ chance of prolonged survival of good quality. ${ }^{12}$ Few patients relish a procedure with a $40 \%$ mortality, and deciding the best time for transplantation remains an unenviable task for the patient and the doctor. A declining quality of personal and family life and a plasma bilirubin concentration above $150 \mu \mathrm{mol} / 1$ and rising are the best indications for seeking advice on transplantation. Patients with primary biliary cirrhosis are often young, but age is less of a bar to transplantation than it was previously. ${ }^{13}$

No treatment will prevent or delay the progression of primary biliary cirrhosis, and formidable difficulties face those seeking such treatments. The cause of the disease and the mechanisms mediating the liver damage are unknown, though immunological abnormalities are considered important, and hence nobody can be certain that treatment is affecting important pathogenetic factors. The prolonged and variable course of the disease ${ }^{14}$ creates difficulties in selecting patients suitable for trials of drug efficacy. These difficulties are then increased by the limited value of blood analyses such as liver function tests for measuring the response to treatment, and liver biopsies cannot be done frequently and are in any case subject to sampling error. Empirical treatments have therefore had to be tested in prolonged controlled trials with death as the only certain measure of outcome, and even this measure will be less available if liver transplantation becomes more common.

Inevitably immunosuppressive and anti-inflammatory drugs have been tried. Corticosteroids have not been subjected to controlled trials owing to their deleterious effects on the skeleton in primary biliary cirrhosis, but uncontrolled observations did not suggest that they were beneficial. ${ }^{15}$ In early trials azathioprine did not look very promising but a later review of a substantial number of patients has suggested beneficial results. ${ }^{16}$ Though azathioprine did not reduce overall mortality, when the adverse effect of a higher plasma bilirubin concentration in treated patients was allowed for statistically a small but significant advantage for azathioprine emerged. The average treated patient then gained about 20 months of life, suffered less incapacity, and had no important adverse drug effects. Unfortunately, about a quarter of the patients were lost to follow up. Therapeutic activists might reasonably treat patients on the basis of these results, especially as more detailed information is unlikely to become available, but the suggestion that azathioprine should become the routine treatment for primary biliary cirrhosis seems excessive.

In both primary biliary cirrhosis and Wilson's disease there is a high copper concentration in the liver, and the proved value of penicillamine in Wilson's disease and its ability to decrease the deposition of immune complexes and to impair collagen maturation led to hopes that this drug would be beneficial in primary biliary cirrhosis. Several controlled trials of penicillamine have now been carried out; initially in some the results were promising, but the eventual outcome has been disappointing. We may reasonably conclude that this drug, which caused serious side effects in about a third of treated patients, should not be used in primary biliary cirrhosis. ${ }^{17}$ Other drugs with antiinflammatory, immunosuppressive, anticollagen, and other actions have been used, but none can be recommended for general use: the trials have usually been in few patients, some 
have had perplexing results, and beneficial results have not been confirmed. Chlorambucil has had beneficial effects on liver function test values and liver histology but no effect on survival. ${ }^{18}$ Colchicine has improved liver function and reduced mortality at four years but surprisingly had no effect on liver histology. ${ }^{19}$ Cyclosporin has reduced plasma alkaline phosphatase and aminotransferase activities in a small group of patients but caused renal damage in each case. ${ }^{20}$ Ursodeoxycholic acid has improved liver function test values but not histology over two years in an uncontrolled trial. ${ }^{21}$

There is little in all this to excite doctors or to raise the hopes of patients. Patients without symptoms have a good prognosis and prolonged treatment with drugs does not seem warranted, while those with advanced disease and liver failure would seem unlikely to benefit from drug therapy. Doctors who feel that they must offer some treatment directed at the disease should limit their efforts to patients with symptoms who do not have liver failure; they could use azathioprine with some hope of benefit and with reasonable chances of avoiding serious side effects. Sceptics would be justified in doing nothing but might consider contributing to controlled trials.

Consultant Physician,

N D C FINLAYSON

Gastrointestinal and Liver Service,

Royal Infirmary,

Edinburgh EH3 9YW
1 Kaplan MM. Primary biliary cirrhosis. N Engl f Med 1987;316:521-8.

2 Christensen E, Crowe J, Doniach D, et al. Clinical pattern and course of disease in primary biliary cirrhosis based on an analysis of 236 patients. Gastroenterolozy 1980;78:236-46.

3 Schaffner F, Klion FM, Latuff AJ. The long term use of cholestyramine in the treatment of primary biliary cirrhosis. Gastroenterology 1965;48:293-8.

4 Datta DV, Sherlock S. Cholestyramine for long term relief of the pruritus complicating intrahepatic cholestasis. Gastroenterology 1966;50:323-32.

5 Javitt NB. Timing of cholestyramine doses in cholestatic liver disease. N Engl $\mathcal{f}$ Med 1974;290:1328-9.

6 Hanid MA, Levi AJ. Phototherapy for pruritus in primary biliary cirrhosis. Lancet 1980;ii:530. Cohen LB, Ambinder EP, Wolke AM, Field SP, Schaffner F. Role of plasmapheresis in primary biliary cirrhosis. Gut 1985;26:291-4.

Duncan JS, Kennedy HJ, Triger DR. Treatment of pruritus due to chronic obstructive live disease. BrMed f 1984;289:22.

9 Beckett GJ, Dewhurst N, Finlayson NDC, Percy-Robb IW. Weight loss in primary biliary cirrhosis. Gut 1980;21:734-8.

10 Arnaud SB. 25-Hydroxyvitamin $D_{3}$ treatment of bone disease in primary biliary cirrhosis. Gastroenterology 1982;137:137-40.

11 Shepherd AN, Bedford GJ, Hill A, Bouchier IAD. Primary biliary cirrhosis, dark adaptometry, electro-oculography and vitamin A state. BrMed $\mathcal{F}$ 1984;289:1484-5.

12 Busuttil RW. Liver transplantation today. Ann Intem Med 1986;104:377-89.

13 Starzl TE, Todo S, Gordon R, et al. Liver transplantation in older patients. $N$ Engl $\mathcal{J}$ Med 1987;316:484-5.

14 Roll J, Boyer JL, Barry D, Klatskin G. The prognostic importance of clinical and histologica features in asymptomatic and symptomatic primary biliary cirrhosis. N Engl f Med 1983;308: $1-7$.

15 Howat HT, Ralston AJ, Varley $\mathrm{H}$, Wilson JAC. The late results of long-term treatment of primary biliary cirrhosis by corticosteroids. Reoue International d'Hepatologie 1966;16:227.

16 Christensen $E$, Neuberger J, Crowe J, et al. Beneficial effect of azathioprine and prediction of prognosis in primary biliary cirrhosis: final results of an international trial. Gastroenterology 1985;89:1084-91.

17 James OFW. D-penicillamine for primary biliary cirrhosis Gut 1985;26:109-13.

18 Hoofnagle JH, Davis GL, Schafer DF, et al. Randomized trial of chlorambucil for primary biliary cirrhosis. Gastroeviterology 1986;91:1327-34.

19 Kaplan MM, Alling DW, Zimmerman HJ, et al. A prospective trial of colchicine for primary biliary cirrhosis. N Engl f Med 1986;315:1448-54.

20 Routhier G, Epstein O, Janossy G, Thomas HC, Sherlock S. Effects of cyclosporin A o suppressor and inducer T lymphocytes in primary biliary cirrhosis. Lancet 1980;ii:1223-6.

21 Poupon R, Chrétien Y, Poupon RE, Ballet F, Calmus Y, Darnis F. Is ursodeoxycholic acid an effective treatment for primary biliary cirrhosis? Lancet 1987;i:834-6.

\section{JPAC: a test for manpower planning}

Successful medical manpower planning has been handicapped by the many years it takes to train doctors for career posts. During this long gestation unpredictable developments may make nonsense of seemingly rational decisions. One important unpredictable factor has been the variable number of doctors in academic and research medicine. Uncertainty about the effect of these doctors on manpower planning prompted the Department of Health and Social Security, the Committee of Vice Chancellors and Principals, the Medical Research Council, and the Joint Consultants Committee to set up the Joint Planning Advisory Committee (JPAC). JPAC's 1986 report has now been published, providing an opportunity to assess progress on its three initial tasks in improving the career structure for hospital doctors.

Firstly, the committee set out to determine the correct number of senior registrar posts needed, both NHS and honorary, by specialty or "specialty group." This seems easy as the relation between senior registrar and consultant posts is direct and the transition period short. JPAC is collecting data on what district health authorities think about their consultant expansion programmes, which is a practical start. But to use the information as the sole basis for calculating the "right" number of senior registrars is a poor substitute for proper planning. Such an approach-which will be even more unsatisfactory if applied to registrars-implies an inability to lead the system. Furthermore, defining specialties and specialty groups is difficult because medical care has become so complex. This is particularly so in medicine and the medical specialties, where the Joint Committee on Higher Medical Training recognises no fewer than 75 different kinds of senior registrar posts. For example, the number of senior registrar posts in renal medicine is an inadequate guide to career opportunities and health care needs in nephrology, general medicine with an interest in nephrology, academic nephrology, or research in kidney disease. More detailed analysis is daunting but hard to avoid, if only because most future consultants in general medicine will be a byproduct of the training of senior registrars in many medical specialties. Fortunately, since its 1986 annual report JPAC has proposed tentative guidelines for resolving this complex matter.

Secondly, JPAC has examined the distributions of NHS and honorary senior registrar posts. Undisclosed or uncounted research and academic posts with senior registrar status have bedevilled attempts to plan, and the priority was to define the size of the problem. Since JPAC began work, however, its secretariat has reached two interesting conclusions: firstly, that it may be almost impossible to count accurately or to control the number of research posts at or about senior registrar level; and, secondly, that it may be unnecessary to do so as the distortion of manpower and career planning is more imaginary than real. Despite its first disclaimer JPAC has produced useful figures for the numbers and distribution of such posts, so far better information than before is now publicly available. There is no limit to the number of academic and research posts that can be created without distorting the career structure-so long as they are not recognised for training. Problems arise when all or part of the time spent in such a post counts towards accreditationas is the case with some registrar training-as an alternative to experience in an NHS senior registrar post. Indeed, JPAC has conceded that it intends "to find out more about 